\title{
The triple challenge of mental health
}

\author{
Peter Zweifel ${ }^{1}$
}

Published online: 30 October 2017

(C) Springer-Verlag GmbH Germany 2017

According to a report by the World Health Organization (2003, p. 8), mental disorders are responsible for a loss of $13 \%$ of disability-free life years (DALYs), compared to 6\% due to HIV/AIDS. Moreover, they account for up to $10 \%$ of physical diseases (33\% in the case of cancer). However, their direct cost is dwarfed by indirect ones, especially at the workplace $[1,2]$. In particular, mental illness in youth may stifle educational attainment and impair careers in later life [3]. In view of this burden of disease, it is stunning to see that only $2 \%$ of public healthcare expenditure (HCE) is devoted to its treatment ([4], p. 38). One possibility of course is that mental health care is not effective; however, according to [4], p. 28-35, there are several evidence-based treatments that are even cost-effective.

\section{Challenge no. 1: explaining this discrepancy}

As behooves an economist, explanation first focuses on the demand side, then on the supply side, concluding with a discussion of potential market and government failure.

\section{Demand-side influences}

Mental illness is still subject to stigma in most countries. This may well be related to its causes, which range from biological (malfunctioning of neurotransmitters, diabetes, chronic pain) to psychological (alcoholism, substance abuse) and on to environmental (death in family, unemployment, divorce). Many people seek to distance themselves

Peter Zweifel

peter.zweifel@uzh.ch

1 Emeritus, University of Zurich, Zurich, Switzerland from individuals suffering from depression, dementia, and schizophrenia (the three most common mental disorders, in decreasing prevalence). However, a particular source of stigma is the fact that people with mental illness are much more likely to be arrested and imprisoned (in the United States, the factor is 4.5 in excess of the general population [5]). According to the same source, more than 50\% of inmates met criteria for mental illness in 2005/06, a figure confirmed for England and Wales [6], with a share of 55\% for neurotic disorder and 65\% for personality disorders (most prevalently anti-social) as of 1997 . These facts go a long way in explaining why patients have a considerable incentive to camouflage mental illness, even in the case of depression, presumably its least stigmatized variant. Indeed, one report [7] estimates that $35 \%$ of patients seeing a primary physician meet the criteria for some form of depression; and even $10 \%$ for its major form. However, the authors argue that primary physicians are likely to treat their patients for apparent physical disease, at considerable extra healthcare expenditure (HCE). In the same vein [8] report on telephone interviews was performed in 1997/98 among 1035 adults suspected of having suffered a mental disorder during these 12 months. No less than $83 \%$ of respondents saw a healthcare provider, most of them, for primary care. Accordingly, a mere $19 \%$ obtained appropriate treatment in this setting.

\section{Supply-side influences}

First of all, physicians are likely to deny any mental disorders, very much like their patients, and for the same fear of stigma and loss of status, although none of the US State Medical Boards surveyed revokes the license even if there was evidence of substance abuse [9]. Thus, primary care physicians without special training (contrary to psychiatrists and psychologists) cannot be counted upon to have much 
empathy for mentally ill patients, although they are their principal contact (see above). This notion is confirmed by Seale et al. [10], who analyzed in detail 322 physician visits by patients with a mental health problem in an attempt to find out whether the advice to ask questions issued by the US Agency of Healthcare Research and Quality had the desired effect. The visits revolved around eight topics, ranging from diabetes, mental health, and family relationships to small talk. Generally, asking at least one question did prolong the visit by an estimated $0.4 \mathrm{~min}(65 \%)$, but only by $0.2 \mathrm{~min}$ if the topic 'mental health' was addressed.

\section{Market and/or government failure?}

The evidence presented can be interpreted as reflecting market failure. It is telling that in industrial countries, expenditure on mental health varies between 5 and $18 \%$ of total HCE, which is higher than the WHO average cited above but still falls short of the prevalence of mental disorders [11]. Australian Medicare is at the low end with 5.3\% as of $2015 / 16$ [12]; yet with $11 \%$ in $2010 / 11$, the far more comprehensive UK National Health Service is just about average [13]. Data for the United States suggest that mental health care is 'sourced out' to the authorities that are also in charge of prisons, since Medicare (the scheme for the aged) spends but $2.6 \%$ of its total HCE on mental health, Medicaid (for the indigent) $10 \%$, but state and federal authorities, $20 \%$ [14]. Therefore, if there is market failure in view of the evidence presented above, it certainly is not neutralized by public policy, pointing to possible government failure. This possibility becomes a reality when individuals with a diagnosis of mental illness are stripped of their political and legal rights, as happens in many countries, mainly (but not only) Communist ones ([15], [16], with references therein).

\section{Challenge no. 2: inconsistency of preferences and economic analysis}

Invariably, economic analysis builds on the assumption of consistent preferences; failing this, neither prediction of behavior nor welfare assessment are possible. Figure 1 illustrates these claims. Let a low-income individual value medical care $M$ and other goods $Y$. The steep original budget constraint indicates that medical care is relatively expensive compared to $Y$ due to a substantial rate of coinsurance; given indifference curve $I_{0}$, the patient's optimum is at point $C_{0}$. Since this individual has a low income, let government subsidize his or her health insurance contribution fully while reducing the rate of coinsurance by $50 \%$. Therefore, the new budget constraint originates from the same point on the $Y$ axis but with half the slope. Given consistent preferences, the prediction is that the individual opts for $C_{1}$ on

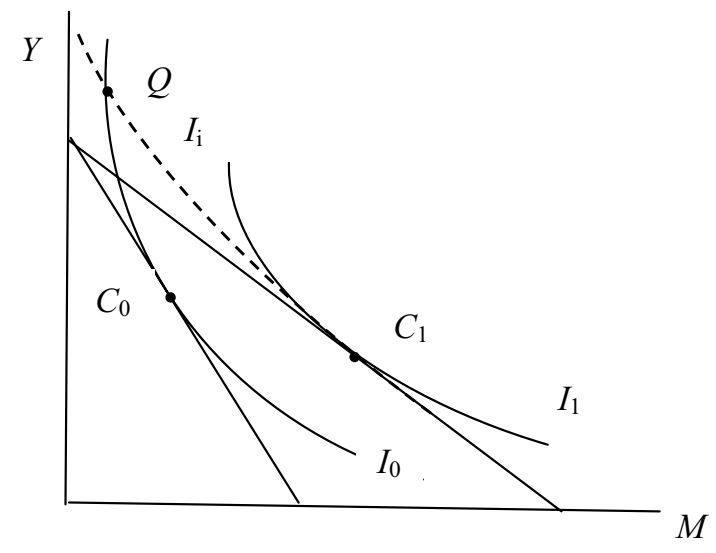

Fig. 1 The consequences of inconsistent ranking of alternatives

the higher-valued indifference curve $I_{1}$, which involves more medical care combined with a somewhat reduced consumption of other goods (if $C_{1}$ were to contain more of both goods, consistency of preferences would not matter since a revealed preference argument could be invoked).

Now let this individual's preferences be inconsistent, reflected by the intersection of indifference curve $I_{0}$ with the dashed indifference curve $I_{\mathrm{i}}$ (i for inconsistent) at point $Q$. Note that to the left of $Q$, curve $I_{0}$ contains combinations of $Y$ and $M$ that dominate $I_{\mathrm{i}}$; yet point $Q$ indicates that these combinations are equivalent to all combinations along $I_{\mathrm{i}}$, a contradiction revealing the inconsistency. On the other hand, since $C_{0}$ is equivalent to point $Q$ which in turn is equivalent to $C_{1}$, the new optimum $C_{1}$ (the same under $I_{1}$ and $I_{\mathrm{i}}$ for simplicity) is no better than $C_{0}$; therefore, there appears to be no gain in welfare. Hence the prediction now is that the individual does not necessarily opt for more medical care; rather, he or she might throw a dice to decide.

In the case of medical care, even economists tend to agree with an adage that is popular within the medical profession, stating that "People don't give a damn about their health as long as they are healthy but are willing to sacrifice all their wealth once they fall ill." In fact, this adage claims that individual preferences are inconsistent, implying that economic theory cannot be applied to decisions bearing on health and medical care. However, available experimental evidence on preference, expressed by willingness to pay for diabetes treatment does not support this claim [17]. Respondents comprised a subgroup without diabetes and a subgroup with diabetes of types I and II; for both of them, a lower risk of hypoglycemia $(R)$ and avoiding weight gain $(W)$ were the two most valued attributes of a new treatment alternative. In addition, their relative valuation $R / W$ was quite similar, with $1.25 / 1$ among the non-diabetes subgroup and 1.00/1 among the diabetes subgroup (the difference between the two ratios is without statistical significance). 
Yet the same adage bears more weight in the case of mentally ill persons, whose cognitive capacity is impaired almost by definition, with a particularly marked effect on young persons whose mental ability presumably is not fully developed. Distinguishing between types of mental disorder, SonugaBarke et al. [18] examined the decision-making capacity of children and adolescents with: (1) attention-deficit/hyperactivity disorder, (2) conduct disorder, (3) depression, and (4) anxiety. Group (1) was typically too quick in reaching a decision, (2) underestimated the impact of negative future events, (3) put excessive emphasis on negative past experience, while group (4) was characterized by excessive risk aversion.

On the other hand, Mondarelli et al. [19] investigated whether patients aged 11 to 18 with acute mental disorders were able to express their preferences concerning medication in a way that would satisfy the 'informed consent' requirement. They used the MacArthur Competence Assessment Tool which provides a patient with the information about the medical/psychiatric condition that needs intervention, the type of treatment being recommended, its risks and benefits, as well as other possible treatments and their probable consequences, and prompts the clinician to ask questions designed to assess the patient's understanding, appreciation, and reasoning regarding treatment decisions. The young patients had experience with up to five pharmaceutical treatments and were found sufficiently competent to consent with the (continuation of) treatment. Interestingly, their decisionmaking capacity was uncorrelated with the psychiatric diagnosis. With a sample size of 22 , the weight of this evidence is limited, however.

Focusing on patients suffering from bipolar disorder (episodes of depression and mania), Yechiam et al. [20] found evidence suggesting that their capacity for decision-making under risk was impaired. They were less successful than the control group in completing the so-called Iowa Gambling Task, which calls for identifying the deck of cards with high financial rewards (out of four), the benchmark being 40-50 trials. However, this finding is again derived from a small sample comprising only 14 acute and 14 remitted patients pitted against a control group of 25 . In the case of depression in particular, indecision is reported to be of particular importance by Tray [21]. While this could reflect indifference between alternatives (which is not problematic for economic theory, see Fig. 1), these mental patients are unable to act (for instance, remaining at point $C_{0}$ or changing to $C_{1}$ ).

\section{Challenge no. 3: choice of agent on behalf of mental health patients}

The principal-agent (PA) model serves as the workhorse of economic analysis for 'regular' HCE: Healthcare providers may use their informational advantage over (potential) patients to pursue their own interest, leaving them with the choice of a payment scheme that is optimal on expectation. Even in that case, however, consumers are hardly able to identify, let alone negotiate an optimal PA contract, calling for a complementary agent in the guise of a (benevolent) health insurer or government [22]. Yet, as found by Zweifel and Frech [23], problems caused by the regulation of contributions (usually community rating) spill over into the structuring of payment, preventing these complementary agents from negotiating in the best interests of their clientele, even if they are benevolent.

To the extent that mental patients exhibit inconsistent preferences, the PA model becomes applicable to begin with because it assumes the uninformed principal to always know what is better and worse, a condition that is not satisfied (see Fig. 1 again). Therefore, the economist's role may well be reduced to identifying the (complementary) agents who can be expected to interpret the inconclusive expressions of preference in the best possible way, as in [24]. Choices range from family members to the psychiatrist and on to the government (see Table 1). For simplicity, agents are again assumed to be willing to act in the mentally ills' best interest except when their own health is at stake. Note that six dimensions of preference can be distinguished, from the when (the patient may have an interest in being considered 'normal' as long as possible) to the where (he or she usually prefers an institution close to family and friends). Also, the what (i.e., the interpretation of the disorder) may matter in that, e.g., the diagnosis of 'depression' carries much less stigma than 'drug abuse'.

Starting with family and relatives, they may be so burdened by taking care of a mentally ill patient that they seek relief by initiating treatment earlier than preferred by the patient (when), possibly in an institution far away (where). On the other hand, they recall the time before the onset of the disorder, enabling them to heed the patient's preferences concerning the interpretation of the disorder (what), the choice of specialist and/or institution (who), and possibly even choice of therapy, especially in the presence of side effects (how). Lay helpers share a possible interest in dumping difficult cases (when, where) while lacking knowledge of the patient's true preferences from earlier times (what). Regarding the who and how, they usually benefit from experience drawn from similar cases. Likewise, workers in social psychiatry hardly ever see clients in their healthy state so have difficulty inferring their unscrambled preferences regarding the when and what. On the other hand, they benefit from experience based on similar cases enabling them to guess preferences regarding the who, how, and where.

Within the medical profession, the typical family physician has known the patient for several years, making it possible to filter his or her true preferences concerning 
Table 1 Agents on behalf of the mentally ill and dimensions of patient preferences

\begin{tabular}{|c|c|c|c|c|c|}
\hline \multirow[t]{2}{*}{ Agent } & \multicolumn{5}{|l|}{ Preference dimension } \\
\hline & $\begin{array}{l}\text { When? Time of initia- } \\
\text { tion of treatment }\end{array}$ & $\begin{array}{l}\text { What? Interpretation } \\
\text { of disorder and its } \\
\text { cause }\end{array}$ & $\begin{array}{l}\text { Who? Choice of spe- } \\
\text { cialist or institution in } \\
\text { charge }\end{array}$ & $\begin{array}{l}\text { How? Choice of } \\
\text { therapy }\end{array}$ & $\begin{array}{l}\text { Where? Place of treat- } \\
\text { ment }\end{array}$ \\
\hline $\begin{array}{l}\text { Family member, } \\
\text { relative }\end{array}$ & $\begin{array}{l}-: \text { Possible interest in } \\
\text { dumping }\end{array}$ & $\begin{array}{l}+: \text { Knowledge of per- } \\
\text { son when healthy }\end{array}$ & $\begin{array}{l}+: \text { Knowledge of per- } \\
\text { son when healthy }\end{array}$ & $\begin{array}{l}+: \text { Knowledge of per- } \\
\text { son when healthy }\end{array}$ & $\begin{array}{l}-: \text { Possible interest in } \\
\text { dumping }\end{array}$ \\
\hline Lay helper & $\begin{array}{l}-: \text { Possible interest in } \\
\text { dumping }\end{array}$ & $\begin{array}{l}-: \text { No knowledge of } \\
\text { person when healthy }\end{array}$ & $\begin{array}{l}+ \text { : Experience based } \\
\text { on similar cases }\end{array}$ & $\begin{array}{l}+: \text { Experience based } \\
\text { on similar cases }\end{array}$ & $\begin{array}{l}-: \text { Possible interest in } \\
\text { dumping }\end{array}$ \\
\hline $\begin{array}{l}\text { Worker in social } \\
\text { psychiatry }\end{array}$ & $\begin{array}{l}-: \text { No know-ledge of } \\
\text { person when healthy }\end{array}$ & $\begin{array}{l}\text {-: No knowledge of } \\
\text { person when healthy }\end{array}$ & $\begin{array}{l}\text { +: Experience based } \\
\text { on similar cases }\end{array}$ & $\begin{array}{l}\text { +: Experience based } \\
\text { on similar cases }\end{array}$ & $\begin{array}{l}\text { +: Experience based } \\
\text { on similar cases }\end{array}$ \\
\hline Family physician & $\begin{array}{l}\text {-: Possible interest in } \\
\text { dumping }\end{array}$ & $\begin{array}{l}+: \text { Knowledge of per- } \\
\text { son when healthy }\end{array}$ & $\begin{array}{l}\text { +: Professional con- } \\
\text { nections }\end{array}$ & $\begin{array}{l}+: \text { Knowledge of per- } \\
\text { son when healthy }\end{array}$ & $\begin{array}{l}-: \text { Possible interest in } \\
\text { dumping }\end{array}$ \\
\hline $\begin{array}{l}\text { Psychiatrist, psycholo- } \\
\text { gist }\end{array}$ & $\begin{array}{l}-: \text { No knowledge of } \\
\text { person when healthy }\end{array}$ & $\begin{array}{l}-: \text { No knowledge of } \\
\text { person when healthy }\end{array}$ & $\begin{array}{l}+: \text { Professional con- } \\
\text { nections }\end{array}$ & $\begin{array}{l}\text { +: Specialized knowl- } \\
\text { edge }\end{array}$ & $\begin{array}{l}+: \text { Professional con- } \\
\text { nections }\end{array}$ \\
\hline Health insurer & -: No know-ledge & -: No knowledge & $\begin{array}{l}+: \text { Knowledge of } \\
\text { network }\end{array}$ & -: No knowledge & -: No knowledge \\
\hline Government & -: No knowledge & -: No knowledge & $\begin{array}{l}+: \text { Knowledge of } \\
\text { provider network }\end{array}$ & -: No knowledge & -: No knowledge \\
\hline Police, judge & - : No knowledge & $\begin{array}{l}-: \text { No knowledge of } \\
\text { person when healthy }\end{array}$ & -: No knowledge & -: No knowledge & -: No knowledge \\
\hline
\end{tabular}

A ' + ' indicates a characteristic facilitating the recognition of the true preferences of the patient, a '-', a characteristic making it more difficult

the when, what, and how; in addition, professional connections facilitate the referral to a specialist who is likely to respect the patient's preferences as well. Only with regard to the time of such a referral (when), there may be an interest in dumping a time-consuming case (see the section on supply-side influences above). In contrast, psychiatrists and psychologists usually see patients only after the onset of the mental disorder, making it difficult to recognize their true preferences regarding the when and what. Their advantage is that in the course of treatment, their specialized knowledge helps them to infer true preferences regarding the how; in addition, their professional connections can help them select an institution in the patient's true interest.

As to the complementary agents referred to above, health insurers know their members from previous billings only, which is insufficient knowledge to infer their ambiguous preferences regarding all dimensions distinguished, with the exception of who thanks to their overview of the professional network. The same holds for the government, represented by administrators working, e.g., in a National Health Service. Finally, police apprehending individuals with mental disorders and judges issuing a verdict on them are almost always ignorant with regard to all five dimensions of their preferences.

In sum, no single potential agent can be counted upon to recognize the true preferences of a mentally ill person.
In many cases, family members and family physicians may be the least imperfect agents in this regard. The economist's remit then becomes the degree of altruism (strength of professional ethics, respectively) that may prevent a possible dumping of the mentally ill patient.

\section{Conclusion}

This editorial starts from the observation that the resources devoted to the treatment of mental illness fall far short of its prevalence and economic relevance. It identifies demand-side (stigma) and supply-side (burden on providers) influences that go some way in explaining this mismatch. A particular difficulty for economic analysis is that (contrary to 'regular' medical care), preferences expressed by persons with mental disabilities may be inconsistent. Potential agents on their behalf therefore are challenged to filter out patients' true preferences with regard to no fewer than five relevant dimensions, viz when treatment is to be initiated, what is the type of disorder, who is to provide it, how is the treatment to proceed, and where it is to be performed. Among eight potential agents distinguished, none can be counted upon to be able to recognize a patient's true preferences along all five dimensions.

In this situation, it seems appropriate for health economists devoted to the analysis of mental illness to focus 
their attention on the altruism and professional ethics of potential agents on the one hand and counteracting circumstances such as work pressure and low remuneration on the other hand.

\section{References}

1. Conti, D.J., Burton, W.N.: The economic impact of depression in a workplace. J. Occup. Med. 36(9), 983-988 (2014)

2. Kessler, R.C., Frank, R.G.: The impact of psychiatric disorders on work loss days. Psychol. Med. 327(4), 861-873 (1997)

3. Kessler, R.C., et al.: Social consequences of psychiatric disorders I: Educational attainment. Am. J. Psychiatry 152(7), 1026-1032 (1995)

4. World Health Organization (WHO). Investing in mental health, Geneva (2003)

5. Lewis A. Incarceration and mental health. https://www.prisonerhealth.org/educational-resources/factsheets-2/incacerationandmental-health (no date)

6. Bird L. The prevalence of mental health problems in the prison setting. Updates 1(3), Mental Health Foundation London UK (no date)

7. Robinson, W.D., Geseke, J.A., Prest, L.A., et al.: Depression treatment: primary care. J. Am. Board Fam. Pract. 18, 79-86 (2005)

8. Young, A.C., Klap, R., Sherbourne, C.D., et al.: The quality of care for depressive and anxiety disorders in the United States. Arch. Gen. Psychiatry 58(1), 55-61 (2001)

9. Hendin, H., Reynolds, C., Fox, D., et al.: Licensing and physician mental health: problems and possibilities. J. Med. Licensure Discip. 93(2), 6-11 (2007)

10. Seale, M.-T., Foo, P.K., Stults, C.D.: Patients with mental health needs are engaged in asking questions, but physicians' responses vary. Health Aff. 32(2), 259-267 (2013)

11. OECD. Focus on health. Paris. https://www.oecd.org/els/healthsystems/Focus-on-health-Making-Mental-Health-Count.pdf (2014). Accessed 29 Sept 2017

12. Australian Institute of Health and Welfare. Expenditure on mental health services. Canberra. https://mhsa.gov.au/resources/expenditure (2016). Accessed 29 Sept 2017
13. Harker, R.: NHS funding and expenditure. House of Commons Library, London (2012)

14. National Institute of Mental Health. Mental health as a percent of all healthcare expenditures by payer, Rockville (2003)

15. Van Voren, R.: Political abuse of psychiatry - a historical overview. Schizophr. Bull. 36(1), 33-35 (2010)

16. Gostlin, L.O., Gable, L.: The human rights of persons with mental disabilities: a global perspective on the application of human rights principles to mental health. Md. Law Rev. 63, 20-124 (2004)

17. Zweifel, P.: Preference measurement: relieving health economics of its Achilles heel. AJ Culyer and G Kobelt. Portrait of a health economist. Essays by colleagues and friends of Bengt Jönsson, pp. 209-217. IHE Swedish Institute of Health Economics, Lund (2014)

18. Sonuga-Barke, E.J.S., Cortese, S., Fairchild, G., et al.: Annual research review: transdiagnostic neuroscience of child and adolescent disorders-differentiated decision-making in attentiondeficit/hyperactivity disorder, conduct disorder, depression, and anxiety. J. Child Psychol. Psychiatry 57(3), 321-346 (2016)

19. Mondarelli, G., Sabatello, U., Lappori, E., et al.: Treatment decision-making capacity in children and adolescents hospitalized for an acute mental disorder: the role of cognitive functioning and psychiatric symptoms. J. Child Adolesc. Psychopharmacol. 27(5), 1-4 (2016)

20. Yechiam, E., Hayden, E.P., Bodkins, M., et al.: Decision making in bipolar disorder: a cognitive modelling approach. Psychiatry Res. 161(2), 146-152 (2008)

21. Tray N. Depression and indecision: trouble making decisions. Healthy Place (2016)

22. Chalkley, M., Malcomson, J.: Contracting for health services with unmonitored quality. Econ. J. 108(449), 1093-1110 (1998)

23. Zweifel, P., Frech, H.E.: Why 'optimal' payment for healthcare providers can never be optimal under community rating. Appl Health Econ Health Policy 14(1), 9-20 (2016)

24. Zweifel, P.: Agency relationships in psychotherapy: an economic analysis. Social Science and Medicine 39(5), 621-628 (1994) 